\title{
Correction to: development of a core outcome set for amblyopia, strabismus and ocular motility disorders: a review to identify outcome measures
}

Samia Al Jabri', Jamie Kirkham ${ }^{2}$ and Fiona J. Rowe ${ }^{1 *}$

\section{Correction to: BMC Ophthalmology 2019 19:47 https://doi.org/10.1186/s12886-019-1055-8}

Following publication of the original article [1], the authors notified us that Fig. 3 was published as a table, when it should actually be a diagram of study countries. In this correction article, Fig. 3 was updated. The original article was corrected.

\section{Author details}

'Department of Health Services Research, University of Liverpool, Waterhouse Building Block B, 2nd Floor, 1-3 Brownlow Street, L69 3GL, Liverpool, UK.

${ }^{2}$ Department of Biostatistics, University of Liverpool, Liverpool, UK.

Received: 26 February 2019 Accepted: 26 February 2019

Published online: 11 March 2019

\section{Reference}

1. Jabri et al. (2019) Development of a core outcome set for amblyopia,

strabismus and ocular motility disorders: a review to identify outcome measures (2019) 19:47. https://doi.org/10.1186/s12886-019-1055-8.

\footnotetext{
* Correspondence: rowef@liverpool.ac.uk

1 Department of Health Services Research, University of Liverpool, Waterhouse

Building Block B, 2nd Floor, 1-3 Brownlow Street, L69 3GL, Liverpool, UK

Full list of author information is available at the end of the article
} 


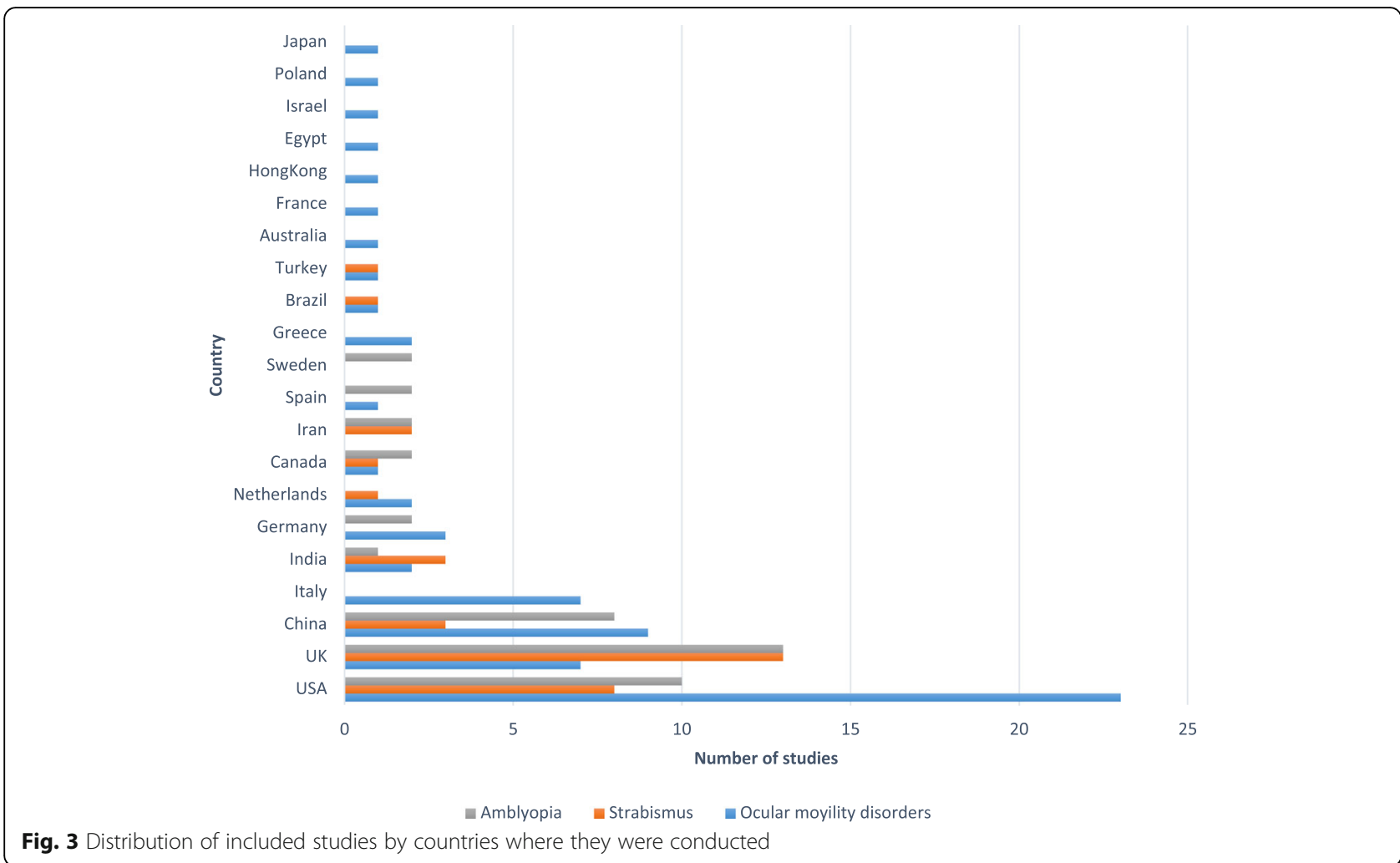

